\title{
Equity Premium Puzzle: A Finnish Review
}

\author{
Nader Shahzad Virk (Corresponding author) \\ Hanken School of Economics \\ P.O. Box 479, 00101 Helsinki, Finland \\ Tel: 358-453-271-333Ｅ-mail: nadir.virk@hanken.fi \\ Accepted: November 16, $2011 \quad$ Published: February 1, 2012 \\ URL: http://dx.doi.org/10.5539/ijef.v4n2p44
}

Received: August 22, 2011

doi:10.5539/ijef.v4n2p44

The research grants from OMX Nasdaq Nordic and Marcus Wallenberg Foundations are acknowledged.

\begin{abstract}
The study provides a comprehensive review on the equity premium puzzle for Finnish stock market. The analysis indicates large risk aversion values for Finnish representative agent to justify the observed equity premium. The negative consumption growth implies a premium for lending in the equilibrium, atypical in reported international evidence. The results for standard consumption model (C-CAPM) show model parameters couldn't replicate the observed returns on the risk-free bond and proxy for aggregate wealth index, same is reported for the reduced sample estimations. The Hansen and Jagannathan (1997) specification measure further illustrates the inability of the model to explain excess equity premium.
\end{abstract}

Keywords: Equity premium, Risk aversion, C-CAPM, Hansen and Jagannathan (1997) specification measure

JEL Classifications: C32, G12

\section{Introduction}

Lucas (1978) and Breeden (1979) developed models for representative agent's maximization problem for the portfolio and consumption choices over different time periods. Since, inter-temporal general equilibrium models occupy an increasingly important place in literature on the margin of macroeconomics and finance. Grossman and Shiller (1981) provided the discrete counterpart of the Breeden (1979) continuous time model. They emphasized investors consider consumption risk while framing their investment decisions. The theoretical elegance of the model interlinks asset prices and payoffs to investors' decisions for consumption and savings in different states of nature and periods. The model has a unique appeal as it bunches together the real and financial sectors of an economy and is constructed under more general frame work than the capital asset pricing model (CAPM) developed by Sharpe (1964) and Lintner (1965).

Hansen and Singleton (1982) noted, under the standard Euler equation, the serial correlation properties of stock returns are related to the changes in consumption and the degree of risk aversion of investors. They approximated the implications using generalized method of moments (GMM) framework. The empirical tests carried by Hansen and Singleton (1982) are referred as consumption CAPM (C-CAPM). The encompassing capacity of the model allows a closed-form solution for investor's temporal choices besides the parameterization of investors risk aversion. Moreover, C-CAPM specifies underlying economic forces that determine the return to risk free rate and the compensation for accepting risk inside the model in sharp contrast to CAPM ${ }^{1}$.

The C-CAPM is the stochastic variant of the neoclassical growth models where the future consumption paths are determined conditioning upon random movements of asset returns. The C-CAPM structure the consumer iso-elastic preferences with power utility function; enveloping intertemporal marginal rate of substitution (IMRS) with changes in marginal utilities for the representative agent which are captured via changes in her consumption levels. Therefore, the assets that yield high returns when marginal utility is also increasing are preferred to smooth consumption in uncertain periods as correspondence for investors risk aversion.

The stochastic variants of growth models have success in replicating the features of macroeconomic real business cycle theory. The empirical results from the macro models when taken to financial market data, besides elegant theoretical construction, are on lower ebb. The most striking of these studies is Mehra and Prescott (1985), demonstrating stock market return over assumed risk free rate is too large to be explained by consumption based risk 
considerations. An explanation for the low premium predicted by standard models is the lowness of risk, measured by the covariance of excess stock return with consumption growth, as in the Hansen and Singleton (1983) C-CAPM.

Equity premium puzzle has taken important place in financial economics $>$ asset pricing literature for last two decades. The puzzle is a huge research topic because of its inquisitiveness regarding the viability of paradigm that is central to capture the characteristics of asset return behaviours and associated riskiness. In general, the studies have focused US market because of long duration data availability. The in-depth studies for the explanation of the equity premia on ex US markets have been scant. The notable studies include Engsted (1998), Hyde and Sherif (2005) using UK data. Lund and Engsted (1996) conducted present value testing for Danish, Swedish, German and UK markets. Hyde, Chuthbertson and Nitzsche (2005) studied different preference specifications for German and French markets using quarterly and annual data frequencies and described that habit formation model only partially reduces the implied risk aversion. Engsted, Mammen and Tanggaard (2001) studied Danish equity premium for varying investment horizons.

Engsted and Moller (2010) studied the important features of Danish equity and bond markets whilst estimating standard CRRA utility and Campbell and Cochrane (1999) habit formation models. The latter study concludes that habit formation model with consumption surplus ratio doesn't perform markedly better than CRRA utility. The results imply equity premium puzzle is robust phenomenon across countries which different economies experience in varying degrees and with explanations. These intricacies surrounding the puzzle entrust us to study the phenomenon also for Finnish equity market.

Viitanen (2004) loosely describes the inefficiency of C-CAPM for Finnish agent. Her work shows Finnish data for non durables neither supports the Hall (1978) random walk model nor the MA (1) model of Mankiw (1982). Oikarinen and Kahra (2001) tested the model with preferences allowed to exhibit a smooth transition with a recession state variable for the equity housing returns and concluded inexplicability of the model for Finnish equity premia. Finnish literature has been devoid of comprehensive study for the explanation of the larger equity return over the risk-free rate.

The reported studies for Finnish market either test the model very causally to boost their associated work or have been gravely limited in scope. The recession in earlier part of 1990s, immense capital market growth in late 1990s, over all negative consumption growth in the sample and historically substantial equity premium makes Finland an important case study for general equilibrium models requiring more focused and in depth perspective. This study takes on the opportunity and describes the salient features of the Finnish investor's intertemporal decision problem under analytically solved substitution and risk parameters.

Additionally, this study goes a bit deeper than reporting analytic solutions and also studies the implications for interest rates using a number of lagged information variables. Consequently the performance of the different information variables is compared in terms of their predictions for interest rates and excess equity premium. The estimations with the standard consumption based asset pricing model are carried out for the full sample (1990:Q1 to 2009:Q2) and sub sample (1995:Q1 to 2009:Q2), excluding the early 1990's recession period, a period with marginally positive consumption growth.

The consumption and portfolio choice problem for the sub sample allows analysis to provide insights under different economic conditions. This analysis ranks tested specifications with Hansen and Jagnannathan (HJ, 1997) distance measure. It has an intuitive economic pricing error interpretation to classify the performance of different specifications. The analytical discussion shows negative consumption growth, its weak co-movement with aggregate stock index, and need for large risk aversion values along with investor's preference for earlier resolution of consumption. The model parameters are meaningful in terms of economic significance that Finnish agent prefer more of consumption today than tomorrow with plausible intertemporal substitution model parameters. The parameterization of the model parameters is more plausible for ex-recession period. However, suffer for increased mispricing than the full sample, as measured with HJ distance. The model predicted risk-free rate is unusually high and fails in producing the observed equity premium, off by a margin to its historical average.

The study proceeds while describing the standard model with power utility and iterated GMM in section 2 . The next section illustartes the data and in sections four and five the analytical and empirical results are discussed respectively. The last section concludes the paper.

\section{The Model}

The standard asset pricing theory states the price of an asset ' $i$ ' at time $t, \mathrm{P}_{\mathrm{t}}$, is the expected value of its future payoff, $\mathrm{X}_{\mathrm{t}+1}$ multiplied with the stochastic discount factor $\mathrm{M}_{\mathrm{t}+1}$ :

$$
P_{i, t}=E_{t}\left[M_{t+1} X_{i, t+1}\right]
$$


$E_{t}$ is the conditional expectation operator with all available information in period t. Future payoff to asset is $X_{t+1}=$ $P_{t+1}+D_{t+1}$ and the stochastic discount factor is governed by the underlying asset pricing model. Under C-CAPM the representative agent/stand in household preference is maximized in an intertemporal choice problem with time separable utility function ${ }^{2}$ of constant relative risk aversion (CRRA) class, $U(c, \gamma)=\frac{c^{1-\gamma}}{1-\gamma}$, where $\gamma \geq 0$ is the Arrow-Pratt notion of relative risk aversion (RRA). The corresponding IMRS implied by solving first order conditions for optimal consumption and portfolio selection is $M_{t+1}=\beta\left(C_{t+1} / C_{t}\right)^{-\gamma}$, where $\beta<1$ describes agents impatience to earlier consumption than later and vice a versa. Defining the gross return (one plus the simple return) $R_{i, t+1}=P_{i, t+1}+D_{i, t+1} / P_{i, t}$, the Euler equation given by the asset pricing relationship from (1) can be established as:

$$
1=E_{t}\left[R_{i, t+1} \beta\left(C_{t+1} / C_{t}\right)^{-\gamma}\right]=E_{t}\left[R_{i, t+1} M_{t+1}\right]
$$

The theoretical construction of the model depicts an agent's marginal utility decreases (increases) with the corresponding consumption increase (decrease). Therefore, the risk adjustments to assets returns should be governed by associated consumption risk. In the complete markets, unique IMRS is ensured such that investors trade with one another to eliminate any idiosyncratic variations in their marginal utilities. Since, risk-averse agent wants to smooth her consumption, and invests in assets promising consistent future consumption streams. To understand the implications of equation (2) the expectation operator is expanded on the right-hand side and further solving leads to the relation,

$$
E_{t}\left[R_{i, t+1}\right]=R_{f, t+1}\left(1-\operatorname{Cov}_{t}\left[R_{i, t+1}, \beta\left(C_{t+1} / C_{t}\right)^{-\gamma}\right]\right)
$$

The relation in (3) holds for all assets in the economy such that quantity of risk is measured by the covariance of the excess return with consumption growth, whereas RRA equals the price of risk. The co-moment of IMRS and asset returns plays the central role in determining the equilibrium expected returns for the assets. Intuitively, the negative covariance in equation (3) demonstrate in equilibrium, the stocks yielding large (low) returns when consumption is high (low) (marginal utility for more consumption is low (high)) are regarded risky and vice a versa. Investors in order to hold such assets command more compensation because accepting risk may jeopardize their future consumption paths, that is, in poor times when marginal utility for consumption is high. The return on risk-free rate is determined inside the model such that

$$
R_{f, t+1}=1 / E_{t}\left[\left(\beta\left(C_{t+1} / C_{t}\right)^{-\gamma}\right)\right]
$$

Under the joint conditional $\log$ normality ${ }^{3}$ of asset returns and consumption growth the $\log$ transformation of equation (3) determines the expected return on the risky asset ' $i$ ':

$$
E_{t}\left[r_{i, t+1}\right]=-\log \beta+\gamma \Delta c_{t+1}-\frac{1}{2}\left[\sigma_{i}^{2}+\sigma_{c}^{2}-2 \sigma_{i c}\right]
$$

The lower case represents the $\log$ for respective random process and $\Delta c_{t+1}=\log \left(C_{t+1} / C_{t}\right)$. Because, the return on the risk free asset is also determined endogenously such that equation (4) gave the log risk free rate such that

$$
r_{f, t+1}=-\log \beta+\gamma \Delta c_{t+1}-\frac{\gamma^{2} \sigma_{c}^{2}}{2}
$$

Subtracting equation (6) from equation (4) leads to log equity premium, that is,

$$
E_{t}\left[r_{i, t+1}-r_{f, t+1}\right]+\frac{\sigma_{i}^{2}}{2}=\gamma \sigma_{i, c}
$$

The expected return over risk-free rate is adjusted for Jensen's inequality for the fact that expectations are drawn for $\log$ returns. The log relations are delineated for the estimation of the implied RRA and impatience parameters for the Finnish investors. Hansen and Jagannathan (1991) provided an alternative perspective solving the relation in equation (4) with respect to SDF and analytically solved for the lower bound ${ }^{4}$ on the volatility of the pricing kernel such that the candidate model may explain the variations in the expected returns.

\subsection{GMM Estimations}

Generalized method of moments (GMM) developed by Hansen (1982) is an extension of classical method of moments. The parameters of interest implied by the model are estimated based upon the imposed moment restrictions. The non linear nature of C-CAPM is conveniently couched with generality of $\mathrm{GMM}^{5}$. Equation (2) is the moment condition to be estimated with iterated GMM across the cross-section of test assets while minimizing for unknown parameters, that is, $\theta=[\beta \gamma]$ such that

$$
\left[\left(R_{i, t+1}\right) M_{t+1}^{\prime}(\theta)\right]-1=0
$$

$M_{t+1}$ is the SDF implied by the C-CAPM and $R_{i, t+1}$ is the gross return for asset ' $i$ '. Let $Z_{t}$ be a matrix of $k$ instruments observable at a period $t$ and $N$ is the number of test assets. The vector for pricing errors $g_{T}(\theta)$ is 
approximated from the $N k$ population moment conditions approximated from the corresponding sample analogues such that

$$
g_{T}(\theta)=\frac{1}{T} \sum_{t=1}^{T}\left[\left(R_{i, t+1} M_{t+1}^{\prime}(\theta)-1\right) \otimes Z_{t}\right]=0
$$

The unknown parameter vector $\theta$ is estimated by minimizing the quadratic form such that

$$
J_{T}=g_{T}(\theta)^{\prime} W g_{T}(\theta)
$$

where $\mathrm{W}$ is $N k \times N k$ weighting matrix for the corresponding moment conditions. The weighting matrix plays an important role in the determination of the exact nature of the minimand. It affects the asymptotic properties of the estimator, and any sub-optimal matrix may produce inconsistent estimates. In the standard Hansen's two-step GMM iteration first step weighting matrix is set to identity to get initial parameter estimates. The first-stage iteration parameters are then used to update the weighting matrix. The optimal weighting matrix, inverse of the residual matrix, from the updated residuals with first-stage parameter estimates is then estimated and is used in the second stage quadratic minimization to get parameter estimates with smallest possible asymptotic variance.

The iteration for estimating parameter vector and updating the weighting matrix applied n-times until the coefficients converge or the change in the objective function in equation (10) is sufficiently small. This approach is called iterated GMM. We employed iterative GMM approach until the model parameters converge to asymptotic distribution using the optimal weighting matrix. The selection of optimal weighing matrix also simplifies the hypothesis testing for GMM approach. Estimator will converge in probability to the true value as long as the population moment analyzed with their sample counterparts hold. If the model is iterated with optimal weighting matrix, then the minimized value of the quadratic function multiplied with the number of observations denoted by $T J_{T}$ converges to $\chi_{N k-q}^{2}$ under the null that imposed moment conditions fits the data well.

Besides, the statistical test $\left(T J_{T}\right)$ for the model specification, this study also computes Hansen and Jagannathan (1997) distance measure such that

$$
\delta=\sqrt{\left[E\left(R_{i, t+1} M_{t+1}(\theta)^{\prime}-1\right)^{\prime} E\left(R_{i, t+1}{ }^{\prime} R_{i, t+1}\right)^{-1} E\left(R_{i, t+1} M_{t+1}(\theta)^{\prime}-1\right)\right]}
$$

It measures the distance of the empirical proxy for model IMRS from the true pricing kernels. The mapping of HJ-distance in GMM framework is straight forward as the $2^{\text {nd }}$ stage weighting matrix is replaced by the inverse of the covariance matrix of the test assets. The constancy of the weighting matrix under HJ methodology allows comparing different asset pricing models. HJ-distance has a strong economic interpretation in terms of percentage pricing errors delineating how much the assets are mispriced by the SDF implied by the underlying asset pricing model and provides an economic misspecification test for the cross-sectional ability of the model. The asymptotic standard error for the HJ distance is computed with delta method as described in Hansen, Heaton and Luttmer (1995).

\section{Data}

This study use quarterly data ${ }^{6}$ from 1990:01 to 2009:02 for the analytic explanations for equity premium puzzle under C-CAPM. The nondurables (ND) and nondurables and services (NDS), provided by ETLA, both are used as approximations for aggregate private consumption. It allows a robustness check in the study for the tested soecifications. In order to get per capita consumption expenditure for the representative agent in the economy the corresponding aggregate is divided by total population in the same quarter.

The market return $\left(r_{m}\right)$ is DataStream all share index for Finnish stock market and $r_{\mathrm{f}}$ is the monthly European interbank offer rate ${ }^{7}$ (EURIBOR) provided by Bank of Finland along with return on 10 year government bond (LGB). Besides, Small-minus-Big (SMB) and High-minus-Low (HML) the Fama and French (1993) risk mimicking factors are also included for Finnish market from Butt and Virk (2011) as additional test assets. The nominal return series and consumption measures to get the real growth rates are deflated with implicit price deflator retrieved from Statistics Finland statfin database.

Table 1 reports summary statistics for variables employed in the study (logarithmic approximations are represented in lower case). The statistics show that returns on stock market and other stock related factors are reasonably higher than bond returns. It explains the very essence of equilibrium based model which regard stocks as highly risk assets but inferior commodities, exhibited in their larger volatility than assumed risk free rate and long rate. The real consumption growth has been negative during the sample period. The fact is same as noted in Oikarinen and Kahra (2002) for Finland, which could be explained by the severe recession experienced during period 1990:Q1-1993:Q3. Viitanen (2004) also reports negative growth for some of sample used in his study. It is arguably for substantial drops in aggregate growth in the pre 1995 period shown in Figure1, when real GDP declined by $21 \%$. 
Since, the full sample consumption growth is negative, we also tested the model for sample period 1995:Q1 to 2009:Q2, a stable period for the economy with positive consumption growth ${ }^{8}$.It provides the opportunity to report models' ability to articulate asset returns with consumption changes under different states of the economy. The autocorrelation coefficients reported in table 1 show that consumption and return on SMB are negatively forecasted from its history and are significant only for consumption growth. The returns on risk-free rate and LGB are positively predictable from its first lag. The return on market index is highly volatile and is unpredictable whereas, SMB and HML are persistent trading strategy as vindicated by auto correlation coefficient.

The $2^{\text {nd }}$ panel in Table 1 describes the correlations structure among the log returns and log consumption growth. The correlations $\left(\rho\left(\Delta \mathrm{nd}, \mathrm{r}_{\mathrm{m}}\right), \rho\left(\Delta \mathrm{nds}, \mathrm{r}_{\mathrm{m}}\right)\right)$ among the real consumption and real stock returns are marginal in quarterly data. However, large variations are observed with increases in horizons such that with 4, 8 or 16 quarters the association parameter ranges from $(0.22,0.35),(0.07,0.24)$ and $(0.3,-0.07)$ with ND and NDS respectively. The implied annual equity premium over risk free rate is healthy $8.8 \%$ with substantially large annualized volatility of 36 percent. It could also explain the very essence of stock returns large premium over risk free rate asset that they are extremely volatile and the investors with CRRA utility function see them as a threat to their future consumption paths and require larger compensation for bearing the risk.

Furthermore, under the standard model the risky assets yielding high premium should be positively correlated with increase in consumption. Nonetheless, these correlations are very low to corroborate with the substantially large premium on them. The negative correlations between consumption growth measures and Fama-French zero cost strategies are reported. For SMB the correlation is very weak although the correlation structure with HML shows it could be rationalized to pay off during bad times for stable consumption paths i.e., when agents marginal utilities are increasing for higher consumptions. The interpretation is better translated as hedging for bad times for its greater negative correlation with NDS as consumption measure than ND, same could be established for returns on risk free rate. The correlation structure for both the consumption measures is quite different for return of HML to rationalize consistently with increasing or decreasing consumption patterns.

In order to see the explanatory power of instrument vectors the predictability regressions are estimated with the corresponding consumption measures. The estimates for the linear explanation implied by the model $\mathrm{R}^{2}$ is reported in Table 2 for both the samples and consumption measures. The set of instrument vectors in the study show weak explanatory power to predict consumption growth. Inst 4 is the only conditioning vector that shows a realistic power to predict the consumption patterns, especially for non durables in the sub sample. It shows it approximately explains approximately $13 \%$ and $10 \%$ of the consumption growth variability in the full sample period whereas for stable period this explanation increases to $20 \%$ and $11 \%$ for ND and NDS respectively. The reported instrument vectors performed significantly better among a number of instrument combinations used and the ones failing to fit the data with Hansen's (1982) over identification test across specifications, and samples were dropped from the analysis.

\section{An Analytic Preview for Finnish Equity Premium}

This section reviews the analytical implications of the Mehra and Prescott (1985) equity premium puzzle for Finnish market. In order to generalize the illustrations, the estimated covariance between consumption growth and return on the aggregate stock index is reported in Table 3 . The estimate $\sigma_{m, c}(1)$ is obtained by multiplying the quarterly standard deviations of market returns and consumption growth with the correlation between them. The implied risk aversion coefficients to match the observed equity premium and return on risk-free rate are 42 and 71 for corresponding consumption growth reported under the column heading RRA (1).

Therefore, in order to see the severity of the puzzle coming from the low correlation between stock returns and consumption growth, $\sigma_{m, c}(2)$ in Table 3 is computed assuming $\rho_{m, c}=1$. The corresponding RRA and impatience coefficients show remarkable diffusion, which is contrary to generalized results for US and other developed economies. However, in consideration to the reported negative growth for the full sample and smooth growth in the sub sample, even these estimates correspond to large price for risk and implied risk-free rate. The effect of the term $\gamma \Delta c_{t+1}$ in equation (6) arising for growth in consumption behaves contrary to its documented equilibrium effect and decreases the interest rates along with the quadratic term known as precautionary savings effect. A representative household with growing consumption is expected to borrow from the credit market to smooth her future consumption streams. The negative consumption growth may enable the stand in household to lend, for the additional supply of money, pressing down the return on risk-free rate.

The estimates from equation (6) for risk-free rate are simulated as shown in figure 2 for different RRA values. The figure shows the sensitivity of risk-free rate in Finnish economy such that even with perfect correlation the model is unable to produce a stable level for risk-free rate with plausible RRA values. The risk-free rate estimates with $\beta=0.97$ 
remain only positive for RRA values under 8 and 12 for ND and NDS respectively. The problem with the estimates is that they are border line solutions and even with small fluctuations in the risk aversion lead to unrealistically high predictions for the risk-free rate, which is counterfactual with respect to the observed constancy in the level of risk-free rate. The reported time preferences in Table (3) are too high that it demands much larger return on risk-free security than the reported average.

The power utility formulation for investor's preferences determines elasticity of intertemporal substitution (EIS) in consumption as the reciprocal of RRA. It's regarded an unwarranted feature with no fundamental economic reason and suggests an agent smoothing her consumption across different states of the world need also steady consumption across periods. Solving the log risk free rate relation in equation (6) with RRA (1) for $(\beta(1))$ provides very high time preference for both ND and NDS respectively. Weil (1989) demonstrated that, with implausibly large RRA coefficients, low level of risk-free rate in equilibrium is achieved only if agents have a low or negative rate of time preference. It's regarded as the risk-free rate puzzle and is an associated issue with equity premium puzzle with power utility specification in under consumption based equilibrium models. All the macroeconomics and growth theory consider values of RRA in the range of 2 to 3. The low value of the risk aversion parameter is evident to the relationship between consumption growth and interest rates. Under the model, the large RRA values will imply a very small value for EIS with agents essentially unwilling to substitute across periods also. Equivalently, this inertia to substitute consumption across periods coupled with large consumption changes over periods should also imply large variations in the interest rates, which is counterfactual given the observed smoothness of short rates over periods and across countries (Cochrane (1997)).

The predictions for risk-free rate for Finland while assuming the usual time preference of 0.99 are negative or highly smoothed for risk aversion values equalling 10 with either consumption measure. The model implied equity premia under noted temporal and risk constraints yield a minuscule fraction of the historical premium. Therefore, along with established large risk aversion values, we also require the agent to have higher time preferences for which we simulated the predictions for interest rates with a time preference parameter equalling 0.97 and below.

It seems reasonable with the annualized 3.6\% return on risk-free security. Cochrane (1997) noted that there are fewer solid reasons to not to object to higher aversion to intertemporal substitution via the consumption-interest rate relation. Nevertheless, the augmentation of temporal and risk parameters still is not able to match the observed equity premium. The best annualized estimate, computed using ND while setting $\beta=0.95$ and RRA equalling 10 , is $2.44 \%$ in comparison to historical large premium of $8.8 \%$ per annum. The implied premium for Finnish representative agent is the best chance on offer from the model to give highest possible prediction for equity premia yet off by a margin to its historical levels. Kocherlakota (1996) delineates that failure is quantitative since the premium predicted by the model is positive though too small to the actual premium with reasonable values for risk aversion.

\section{Empirical Estimations}

The C-CAPM is tested for two different model specifications to evaluate the cross-sectional ability of the model. Firstly, the specification is with returns on the aggregate stock index, risk free rate and LGB and the $2^{\text {nd }}$ specification also includes returns on SMB and HML risk factors for Finnish market along with the test assets in $1^{\text {st }}$ specification. These specifications are then re-estimated for the ex-recession sub sample. The implied log risk free rate and log equity premium are also reported to see the predictions from the model across periods. Table 4 reports the iterated GMM estimations for the full sample for both specifications. The imposed moment conditions are validated by the Hansen's (TJ-test) across all specifications. The $\beta$ estimates are low with NDS than ND across both specifications using Inst1, Inst2 and Inst3. Because of the high time preference with NDS larger imprecision in the predicted level of risk-free rate is noted than ND across all the models. The risk aversion estimates are more plausible with NDS than with ND as the consumption measure. Since, the correct risk aversion parameters with ND are only reported for Inst5 in both the specifications along with Inst3 in the specification I although imprecise. In comparison, the RRA estimates with NDS are implausible for Inst4 in the specification I and for Inst1 and Inst2 in specification II. However, the plausibility is marked with large sampling errors for RRA estimates in the full sample. Ignoring the imprecision of RRA doesn't still fix the problem in yielding reasonable level for risk-free rate and further resolution to observed equity premium.

The projected risk free rates in general, across all the models, are over predicted. However, larger mispricing is recorded with NDS as the consumption measure. The performance of instrument vectors can be evaluated in terms of average inaccuracy for the model predicted rate to its expected return. The projections for risk-free rate are over estimated in a range of $0.53 \%$ to $0.9 \%$ per quarter for ND whereas for NDS the quarterly mispricing is in the range of $0.85 \%$ to $1.15 \%$ on average for all the incorporated instruments. The predicted equity premia is off by a margin to 
realized level of $2.2 \%$ per quarter or at times negative as reported in Table 4 . The only instance with a reasonable level for risk-free rate is reported in the specification, I with NDS instrumented with vector 1 , that is, $0.1 \%$ per quarter. However, the setting fails to produce the substantial large equity premium. The results show models with negative risk aversion values project negative premium. The HJ-distance measure also describes the non-suitability of the model implied IMRS to price cross-section of assets, same is reported for estimation in specification II. The average mispricing increases by $20 \%$ with inclusion of SMB and HML portfolios as compared with specification I.

The reported results in table 5 provide reasonably better temporal and risk estimates than the full sample. The RRA estimates particularly are more meaningful with ND than NDS. The parameter values with instrument vectors 2, 4 and 5 tend to be more sensible across both the specifications with small sampling errors. The average inaccuracy is reasonably lower than the full sample for predicting the level for observed risk free rate with ND. The tranquil period estimations fail to produce the substantial equity premium rather the projected estimate is further contracted than the full sample projections. However, the disparity of model SDF to approximate the true pricing kernel spoils the reported better estimates for impatience parameter, RRA, risk free rate in Table 5 to full sample counterparts. The results from the sub sample can be generalized in terms of the statistical validation of the model. Otherwise the dismal performance by the model is aggravated in terms of economic measure such that the reported mispricing noted with $\mathrm{HJ}$ distance is ballooned to $120 \%$ on average and for specification II is reported $140 \%$ on average reported in Table 5 .

The results from both the samples can be summarised with model's inability to produce a reasonable level of risk parameters to yield matching rates to historical averages of risk-free rate and equity premium. In general, the results exhibit sensitivity to consumption type, number of test assets, instrument vectors (for the sub sample estimations) and estimation samples. The more reasonable estimates for RRA are predicted with NDS consumption with the employed instrument vectors in both the samples and same is established for ND in the tranquil period. However, the model implied IMRS fail to approximate the true SDF to price cross-section of assets, and this inability is compounded when the model is confronted with additional assets and is extremely severe for the sub sample estimations.

\section{Conclusion}

This study concludes large equity premium is a robust phenomenon in Finland historically in line with the reported international evidence. The negative consumption growth in Finland manifests strong saving motives for the representative agent, with a preference for consumption today in the full sample analysis. The consumption is marginally positive in the sub sample but still exhibits high time preferences. The covariance between consumption growth and stocks return has been low in the data. Therefore, large RRA values are to assume to match the observed equity premium. The larger risk exposure (18\% quarterly stock index volatility) for holding stocks is argued the probable reason for agents to have the larger aversion to risk and also the stand-in household prefers earlier consumption than later consistent with economic theory. The analytically large values of RRA are consequence of low consumption covariance risk further complicating the issue and giving unrealistically high predictions for risk free rate, that is, Weil's (1989) associated risk-free rate puzzle.

The negative consumption growth implies a premium for lending in Finland contrary to borrowing need with positive consumption growth in equilibrium. The results show estimations are sensitive to selection of assets, consumption measure, instruments and samples. The model parameters predict low returns to reconcile with historical averages. The inability of C-CAPM is economically justified with the HJ-distance measure with reportedly large mispricing across the specifications and samples. The mispricing in the sub sample is to some extreme extent to be argued rational and provide lowness of the model to approximate the true model. There are a number of scenarios to move on, that is, to study the Finnish market with more generalized preference structure as of Epstein and Zin $(1989,1991)$ which separates investors risk and time preferences. Habit formation models from Abel (1991), Constantinides (1990) and Campbell and Cochrane could be the other possibility to explore the Finnish equity puzzle while keeping intact investors risk aversion to some rational economic structure and without raising the risk-free rate level.

\section{References}

Abel, A.B. (1990). Asset prices under habit formation and catching up with the Joneses. American Economic Review Papers and Proceedings, 80, 38-42.

Breeden, D. (1979). An intertemporal asset pricing model with stochastic consumption and investment opportunities, Journal of Financial Economics, 7(3), 265-296. http://dx.doi.org/10.1016/0304-405X(79)90016-3 
Campbell, J.Y., \& Cochrane, J, H. (1999). By force of habit: a consumption-based explanation of aggregate stock market behaviour. Journal of Political economy, 107(2), 205-251.

Campbell, J.Y. (1999). Asset prices, Consumption, and the Business Cycle. J.B. Taylor and M. Woodford, eds., Handbook of Macroeconomics, 1, 1231-1303.

Cochrane, J.H. (1997). Where is market going? Uncertain facts and novel theories. Economic Perspectives, 21(6), 3-37.

Constantinides, G. M. (1990). Habit Formation: A Resolution of the Equity Premium Puzzle. Journal of Political Economy 98 (3): 519-43. http://dx.doi.org/10.1086/261693

Engsted, T., \& Moller, S.V. (2010). An iterated GMM procedure for estimating the Campbell-Cochrane habit formation model, with an application to Danish stock and bond returns. International Journal of Finance and Economics, 15(3), 213-227.

Engsted, T., Mammen, E., \& Tanggaard, C. (2001). Evaluating the C-CAPM and the Equity Premium Puzzle at Short and Long Horizons: A Markovian Bootstrap Approach. Unpublished paper, Aarhus School of Business, Denmark.

Engsted, T. (1998). Evaluating the consumption-capital asset pricing model using Hansen-Jagannathan Bounds: Evidence from UK International. Journal of Finance \& Economics, 3(4), 291-302. http://dx.doi.org/10.1002/(SICI)1099-1158(199810)3:4<291::AID-IJFE87>3.0.CO;2-U

Epstein L.G., \& Zin S.E. (1989). Substitution, risk aversion and the temporal behavior of consumption and asset returns: a theoretical framework. Econometrica, 57(4), 937-969. http://dx.doi.org/10.2307/1913778

Epstein, L.G., \& Zin, S.E. (1991). Substitution, risk aversion, and the temporal behavior of consumption and asset returns: an empirical analysis. Journal of Political Economy, 99, 263-286. http://dx.doi.org/10.1086/261750

Grossman, S.J., \& Shiller, R.J. (1981). The determinants of the variability of stock market prices. American Economic Review, 71, 222-227.

Hall, R.E. (1978). Stochastic Implications of the Cycle-Permanent Income hyposthesis: Theory and Evidence. Journal of Political Economy, 86(6), 971-987. http://dx.doi.org/10.1086/260724

Hansen, L. P. (1982). Large sample properties of generalized method of moments estimators. Econometrica, 50(4), 1029-1054. http://dx.doi.org/10.2307/1912775

Hansen, L.P., \& K.J. Singleton. (1982). Generalized instrumental variables estimation of nonlinear rational expectations models. Econometrica, 50,1269-1288. http://dx.doi.org/10.2307/1911873

Hansen, L.P., \& Singleton, K.J. (1983). Stochastic Consumption, Risk Aversion, and the Temporal Behaviour of Asset Returns. Journal Political Economy, 91, 249-268. http://dx.doi.org/10.1086/261141

Hansen L.P., Heaton J., \& Luttmer E. (1995). Econometric evaluation of asset pricing models. Review of Financial Studies, 8, 237-274. http://dx.doi.org/10.1093/rfs/8.2.237

Hansen L.P., \& Jagannathan R. (1997). Assessing specification errors in stochastic discount factor models. Journal of Finance, 52, 557-590. http://dx.doi.org/10.2307/2329490

Hyde, S., \& Sherif, M. (2005). Consumption asset pricing models: Evidence from the UK. The Manchester School, 73, 343-363. http://dx.doi.org/10.1111/j.1467-9957.2005.00450.x

Hyde, S., Cuthbertson, K., \& Nitzsche, D. (2005). Resuscitating the C-CAPM: Empirical evidence from France and Germany. International Journal of Finance and Economics, 10,337-357. http://dx.doi.org/10.1002/ijfe.282

Kocherlakota, N.R. (1996). The equity premium: it's still a puzzle, Journal of Economic Literature, 34, 42-71.

Lintner, J. (1965). The valuation of risk assets and selection of risky investments in stock portfolios and capital budgets. Review of Economics and Statistics, 47(1), 13-37. http://dx.doi.org/10.2307/1924119

Lucas Jr., R.E. (1978). Asset prices in an exchange economy. Econometrica, 46, 1429-1445. http://dx.doi.org/10.2307/1913837

Lund, J., \& Engsted, T. (1996). GMM and present value tests of the C-CAPM: Evidence from the Danish, German, Swedish and UK stock markets. Journal of International Money and Finance, Vol. 15(4), 497-521. http://dx.doi.org/10.1016/0261-5606(96)00018-6

Mankiw,G:N. (1982). Hall's Consumption Hypothesis and Durable Goods, Journal of Monetary Economics. The Quarterly Journal of Economics, 29, 97-112. 
Newey, W.K., \& West, K.D. (1987) Hypothesis testing with efficient method of moments estimation. International Economic Review, 28, 777-787. http://dx.doi.org/10.2307/2526578

Oikarinen, E., \& Kahra, H. (2002). A Consumption based explanation of equity and housing property returns. presented at Pacific RIM real estate society Conference, 21-23 January 2002, Christchurch, New Zealand.

Sharpe, W.F. (1964). Capital asset prices: A theory of market equilibrium under conditions of risk. Journal of Finance, 19(3), 425-442. http://dx.doi.org/10.2307/2977928

Viitanen, J. (2004). Consumption based CAPM model with Finnish evidence: Introductory Essay with Summaries of Other Chapters, University of Joensuu.

Weil, P. (1989). The equity premium puzzle and the risk-free rate puzzle. Journal of Monetary Economy, 24, 401-421. http://dx.doi.org/10.1016/0304-3932(89)90028-7

\section{Notes}

Note 1. The theoretical limitations of CAPM require determination of returns on market index and risk free rate outside the model. Such that equilibrium is achieved and return structures for all other stocks are determined with their risk sensitivities with systematic risk disallowing idiosyncratic risks.

Note 2. The power utility is assumed for entailing important features of scale invariance for stationarity of resulting equilibrium return process and allowing for aggregation and a stand in representative agent formulation that is independent of initial income levels. The less desirable property of the utility formation in the model is that it relates investors time preferences with risk preferences, which has no fundamental economic rationale.

Note 3. If a random variable $\mathrm{X}$ is conditionally lognormally distributed, it has the convenient property that $\log E_{t}[X]=E_{t}[\log X]+\frac{1}{2} \operatorname{Var}_{t}[\log X]$.

Note 4. They solved the relation in equation (4) with generalized candidate SDF and analytically described that the model to explain the cross sectional variations on asset returns in the economy has to follow the lower bound on the volatility of SDF, given by the relation: $\sigma_{m} \geq\left|\frac{E_{t}\left[r_{i, t+1}-r_{f, t+1}\right]+\frac{\sigma_{i}^{2}}{2}}{\sigma_{i}}\right|$.

Note 5. Other estimations techniques like ordinary least squares, instrumental variables estimators, and two-stage least squares, and in some cases maximum likelihood can easily be described in the GMM framework.

Note 6. The selection of data period is restricted because this study employs SMB and HML Fama and French (1993) risk mimicking factors from Butt and Virk (2011, work in progress) for Finnish stock market.

Note 7. The series for risk free rate is completed with HELIBOR (Helsinki interbank offered rate) for period prior to January 1999.

Note 8 . The logarithmic consumption growth for the sub sample is $0.23 \%$ and $0.33 \%$ per annum for ND and NDS with corresponding annualized volatility of $3.48 \%$ and $2.08 \%$. It is also noteworthy that the global recession is also evident from Finnish consumption patterns in Figure 1 as the consumption drops from 2008Q1. The data in the sub sample is also weakly correlated with aggregate wealth index and unpredictable form its history alike full sample.

Table 1. Summary Statistics

\begin{tabular}{|c|c|c|c|c|c|c|c|c|c|c|}
\hline & $\mu_{\mathrm{i}}[\mathrm{se}]$ & $\sigma_{\mathrm{i}}$ & $\rho(1) \quad[\mathrm{se}]$ & $\mathrm{r}_{\mathrm{f}}$ & $\mathrm{r}_{\mathrm{m}}$ & $\mathrm{r}_{\mathrm{smb}}$ & $\mathrm{r}_{\mathrm{hml}}$ & $\mathrm{r}_{\mathrm{b}}$ & $\Delta \mathrm{nd}$ & $\Delta$ nds \\
\hline $\mathrm{r}_{\mathrm{f}}$ & $3.6 \quad[0.41]$ & 1.72 & $0.72[0.08]$ & 1 & & & & & & \\
\hline$r_{m}$ & $12.4[8.32]$ & 36.39 & $0.01 \quad[0.11]$ & -0.13 & 1 & & & & & \\
\hline$r_{\mathrm{smb}}$ & 4.88 [4.69] & 20.74 & $-0.26[0.11]$ & 0.04 & -0.26 & 1 & & & & \\
\hline $\mathrm{r}_{\mathrm{hml}}$ & 0.19 [5.19] & 22.93 & $0.13[0.11]$ & 0.04 & -0.36 & 0.23 & 1 & & & \\
\hline$r_{b}$ & $4.4 \quad[0.30]$ & 1.46 & $0.64[0.09]$ & 0.84 & -0.05 & -0.01 & -0.06 & 1 & & \\
\hline$\Delta \mathrm{nd}$ & $-0.96[0.91]$ & 3.92 & $-0.38[0.11]$ & 0.03 & 0.14 & -0.01 & -0.13 & 0.16 & 1 & \\
\hline$\Delta \mathrm{nds}$ & $-0.58[0.72]$ & 2.85 & $-0.28[0.10]$ & -0.12 & 0.11 & -0.01 & -0.17 & 0.14 & 0.72 & 1 \\
\hline
\end{tabular}

The annualised mean and standard deviation of log series are presented in the $1^{\text {st }}$ panel whereas, all remaining statistics in both panels are estimated with real series. The reporting of log expectations and standard deviations are considered for convenient characteristic of time scaling and furbishing annual equity premium in Finnish market. The quarterly mean and standard deviation can easily be computed by dividing the series by 4 and 2 respectively. The third column reports autocorrelation coefficient at first lag. The next panel in the table reports the correlations coefficients between the asset returns and consumptions growth. 
Table 2. The Explanatory Power of the Sets of Instrumental Variables

\begin{tabular}{lllll}
\hline & \multicolumn{2}{c}{ Full Sample } & \multicolumn{2}{c}{ Sub Sample } \\
& ND & NDS & ND & NDS \\
\hline Inst1 & 0.07 & 0.95 & 3.17 & 0.65 \\
Inst2 & 1.18 & 2.05 & 4.51 & 2.7 \\
Inst3 & 0.23 & 0.49 & 0.24 & 0.39 \\
Inst4 & 12.51 & 9.83 & 20.02 & 10.58 \\
Inst5 & 0.47 & 1.41 & 1.77 & 1.05 \\
\hline
\end{tabular}

The model implied $\mathrm{R}^{2}$ are reported from equation $\Delta c_{i, t}=Z_{i, t} B^{\prime}+e_{t}$ where $\Delta c_{i, t}$ and $Z_{i, t}$ are consumption measure and set of instrument variables respectively. $B$ is the coefficient row vector and $e_{t}$ implies residual vector from the predictability regression. The set of instrument vectors used in the study are Inst1 $=\left(\right.$ Constant, $\left.R_{m, t}, R_{m, t-1}\right)$, Inst2 $=\left(\right.$ Constant, $\left.R_{m, t}, R_{f, t}, L_{B}\right)$, Inst3 $=\left(\right.$ Constant, $\left.R_{m, t}, D_{t}\right)$, Inst $4=\left(\right.$ Constant, $C_{t} / C_{t-1}, L B_{t}$, $\left.\mathrm{R}_{\mathrm{f}, \mathrm{t}}\right)$,Inst5= $\left(\right.$ Constant, $\left.\mathrm{R}_{\mathrm{m}, \mathrm{t}}, \mathrm{DY} \mathrm{Y}_{\mathrm{t}}, \mathrm{PER}_{\mathrm{t}}\right)$. DY and PER are the dividend yield and price to earnings ratios for the aggregate stock index used in the study for Finland.

Table 3. Historical co-moments and Implied Time and Risk Preferences

\begin{tabular}{lllllll}
\hline & $\sigma_{m, c}(1)$ & $\sigma_{m, c}(2)$ & RRA(1) & RRA $(2)$ & $\beta(1)$ & $\beta(2)$ \\
\hline$\Delta \mathrm{ND}$ & 0.05 & 0.36 & 41.95 & 6.18 & 0.63 & 0.97 \\
$\Delta \mathrm{NDS}$ & 0.03 & 0.26 & 71.17 & 8.49 & 0.53 & 0.97 \\
\hline
\end{tabular}

In the table the long run co-moments of aggregate consumption and stock market return are reported under heading $\sigma_{i, c}(1)$ and $\sigma_{i, c}(2)$ with actual correlation and supposed unit correlation among them respectively. Subsequently, RRA(1) and RRA(2) describes the analytical solutions for the Finnish stand in household's risk preferences with estimated co-moments in column 1 and 2. The corresponding time preferences are also reported in column 5 and 6 .

Table 4. Full Sample C-CAPM Estimations with Iterated GMM

\begin{tabular}{|c|c|c|c|c|c|c|c|c|c|c|}
\hline \multicolumn{6}{|c|}{ Non Durables } & \multicolumn{5}{|c|}{ Non Durables and Services } \\
\hline & Inst1 & Inst2 & Inst3 & Inst4 & Inst5 & Inst1 & Inst2 & Inst3 & Inst4 & Inst5 \\
\hline \multicolumn{11}{|c|}{ Specification I } \\
\hline$\beta$ & $\begin{array}{l}0.99 \\
(0.020)\end{array}$ & $\begin{array}{l}0.99 \\
(0.003)\end{array}$ & $\begin{array}{l}0.98 \\
(0.019)\end{array}$ & $\begin{array}{l}0.98 \\
(0.001)\end{array}$ & $\begin{array}{l}0.98 \\
(0.002)\end{array}$ & $\begin{array}{l}0.98 \\
(0.003)\end{array}$ & $\begin{array}{l}0.98 \\
(0.001)\end{array}$ & $\begin{array}{l}0.97 \\
(0.015)\end{array}$ & $\begin{array}{l}0.98 \\
(0.002)\end{array}$ & $\begin{array}{l}0.98 \\
(0.001)\end{array}$ \\
\hline$\gamma$ & $\begin{array}{l}-3.09 \\
(16.54)\end{array}$ & $\begin{array}{l}\mathbf{- 3 . 6 3} \\
(1.13)\end{array}$ & $\begin{array}{l}0.29 \\
(7.1)\end{array}$ & $\begin{array}{l}-0.21 \\
(0.12)\end{array}$ & $\begin{array}{l}0.21 \\
(0.53)\end{array}$ & $\begin{array}{l}1.47 \\
(2.45)\end{array}$ & $\begin{array}{l}0.07 \\
(0.16)\end{array}$ & $\begin{array}{l}4.46 \\
(7.31)\end{array}$ & $\begin{array}{l}\mathbf{- 2 . 6 9} \\
(0.55)\end{array}$ & $\begin{array}{l}0.1 \\
(0.4)\end{array}$ \\
\hline $\begin{array}{l}\text { TJ-test } \\
p \text {-value }\end{array}$ & $\begin{array}{l}6.7 \\
{[0.46]}\end{array}$ & $\begin{array}{l}10.32 \\
{[0.41]}\end{array}$ & $\begin{array}{l}6.28 \\
{[0.51]}\end{array}$ & $\begin{array}{l}10.7 \\
{[0.38]}\end{array}$ & $\begin{array}{l}8.16 \\
{[0.61]}\end{array}$ & $\begin{array}{l}7.21 \\
{[0.41]}\end{array}$ & $\begin{array}{l}10.27 \\
{[0.42]}\end{array}$ & $\begin{array}{l}6.34 \\
{[0.50]}\end{array}$ & $\begin{array}{l}(10.87 \\
{[0.37]}\end{array}$ & $\begin{array}{l}8.17 \\
{[0.61]}\end{array}$ \\
\hline $\begin{array}{l}\delta \\
\operatorname{sigma}(\delta)\end{array}$ & $\begin{array}{l}0.44 \\
(0.23)\end{array}$ & $\begin{array}{l}0.44 \\
(0.23)\end{array}$ & $\begin{array}{l}0.43 \\
(0.24)\end{array}$ & $\begin{array}{l}0.43 \\
(0.23)\end{array}$ & $\begin{array}{l}0.43 \\
(0.24)\end{array}$ & $\begin{array}{l}0.42 \\
(0.24)\end{array}$ & $\begin{array}{l}0.43 \\
(0.23)\end{array}$ & $\begin{array}{l}0.40 \\
(0.24)\end{array}$ & $\begin{array}{l}0.44 \\
(0.23)\end{array}$ & $\begin{array}{l}0.43 \\
(0.23)\end{array}$ \\
\hline$r_{f}$ & 1.19 & 1.72 & 1.57 & 1.8 & 1.64 & 1.34 & 1.73 & 2.22 & 1.96 & 1.64 \\
\hline$r_{m}-r_{f}$ & -0.15 & -0.17 & 0.01 & -0.01 & 0.01 & 0.04 & 0.002 & 0.13 & -0.08 & 0.003 \\
\hline \multicolumn{11}{|c|}{ Specification II } \\
\hline$\beta$ & $\begin{array}{l}0.99 \\
(0.004)\end{array}$ & $\begin{array}{l}0.99 \\
(0.003)\end{array}$ & $\begin{array}{l}0.99 \\
(0.005)\end{array}$ & $\begin{array}{l}0.98 \\
(0.000)\end{array}$ & $\begin{array}{l}0.98 \\
(0.001)\end{array}$ & $\begin{array}{l}0.98 \\
(0.004)\end{array}$ & $\begin{array}{l}0.98 \\
(0.001)\end{array}$ & $\begin{array}{l}0.98 \\
(0.002)\end{array}$ & $\begin{array}{l}0.98 \\
(0.001)\end{array}$ & $\begin{array}{l}0.98 \\
(0.001)\end{array}$ \\
\hline$\gamma$ & $\begin{array}{l}-7.22 \\
(8.39)\end{array}$ & $\begin{array}{l}\mathbf{- 3 . 3 1} \\
(0.84)\end{array}$ & $\begin{array}{l}-2.76 \\
(2.16)\end{array}$ & $\begin{array}{l}-0.07 \\
(0.07)\end{array}$ & $\begin{array}{l}0.46 \\
(0.34)\end{array}$ & $\begin{array}{l}-5.25 \\
(5.07)\end{array}$ & $\begin{array}{l}\mathbf{- 1 . 2} \\
(0.31)\end{array}$ & $\begin{array}{l}1.51 \\
(1.06)\end{array}$ & $\begin{array}{l}0.53 \\
(0.3)\end{array}$ & $\begin{array}{l}\mathbf{1 . 9 2} \\
(0.77)\end{array}$ \\
\hline TJ-test & 10.27 & 9.87 & 9.21 & 11.21 & 10.85 & 10.26 & 9.77 & 9.98 & 17.99 & 10.26 \\
\hline p-value & {$[0.67]$} & {$[0.94]$} & {$[0.76]$} & {$[0.89]$} & {$[0.90]$} & {$[0.67]$} & {$[0.94]$} & {$[0.93]$} & {$[0.16]$} & {$[0.67]$} \\
\hline $\begin{array}{l}\delta \\
\operatorname{sigma}(\delta)\end{array}$ & $\begin{array}{l}0.61 \\
(0.20)\end{array}$ & $\begin{array}{l}0.60 \\
(0.21)\end{array}$ & $\begin{array}{l}0.59 \\
(0.21)\end{array}$ & $\begin{array}{l}0.58 \\
(0.21)\end{array}$ & $\begin{array}{l}0.58 \\
(0.21)\end{array}$ & $\begin{array}{l}0.60 \\
(0.21)\end{array}$ & $\begin{array}{l}0.59 \\
(0.21)\end{array}$ & $\begin{array}{l}0.58 \\
(0.21)\end{array}$ & $\begin{array}{l}0.58 \\
(0.21)\end{array}$ & $\begin{array}{l}0.57 \\
(0.21)\end{array}$ \\
\hline$r_{f}$ & 1.89 & 1.87 & 1.28 & 1.79 & 1.67 & 2.16 & 1.83 & 1.88 & 1.6 & 1.91 \\
\hline$r_{m}-r_{f}$ & -0.34 & -0.16 & -0.13 & 0 & 0.02 & -0.15 & -0.03 & 0.04 & 0.02 & 0.06 \\
\hline
\end{tabular}

Table reports the full sample C-CAPM estimations with iterated GMM. First panel reports the estimation output with aggregate stock index return, returns on risk free bond and long term bond in specification I and specification II adds SMB and HML as test assets to the cross section of returns in specification I. In each panel against the subsequent instrument vector model time and risk preferences are reported in front of row headings $\beta$ and $\gamma$ respectively. The standard errors for the model estimates are given in ().TJ-test is the Hansen's moment identification statistic reported with p-value in []. $\delta$ is the HJ-distance measure computed as in equation (11) section 2.1 and sigma( $\delta$ ) reports the asymptotic standard errors for the measure computed in (12) in the same section. The last two rows report the log risk free rate and log equity premia in percentage points estimated 
from the corresponding setting's time and risk aversion parameters. The coefficients significant at $5 \%$ and below critical values are presented in bold font. The employed instrument vectors are such that

Inst $1=\left(\right.$ Constant, $\left.R_{m, t}, R_{m, t-1}\right)$

Inst2 $=\left(\right.$ Constant, $\left.\mathrm{R}_{\mathrm{m}, \mathrm{t}}, \mathrm{R}_{\mathrm{f}, \mathrm{t}} \mathrm{LGB}_{\mathrm{t}}\right)$

Inst $3=\left(\right.$ Constant, $\left.\mathrm{R}_{\mathrm{m}, \mathrm{t}}, \mathrm{DY}_{\mathrm{t}}\right)$

Inst $4=\left(\right.$ Constant, $\left.\mathrm{C}_{\mathrm{t}} / \mathrm{C}_{\mathrm{t}-1}, \mathrm{LGB}_{\mathrm{t}}, \mathrm{R}_{\mathrm{f}, \mathrm{t}}\right)$

Inst5 $=\left(\right.$ Constant, $\left.\mathrm{R}_{\mathrm{m}, \mathrm{t}}, \mathrm{DY}_{\mathrm{t}}, \mathrm{PER}_{\mathrm{t}}\right)$

Table 5. Ex-Recession Period C-CAPM Estimations with Iterated GMM

\begin{tabular}{|c|c|c|c|c|c|c|c|c|c|c|}
\hline & \multicolumn{5}{|c|}{ Non Durables } & \multicolumn{5}{|c|}{ Non Durables and Services } \\
\hline & Inst1 & Inst 2 & Inst 3 & Inst 4 & Inst 5 & Inst1 & Inst 2 & Inst 3 & Inst 4 & Inst 5 \\
\hline \multicolumn{11}{|c|}{ Specification I } \\
\hline \multirow[t]{2}{*}{$\beta$} & 0.99 & 0.98 & 0.98 & 0.98 & 0.99 & 0.99 & 0.98 & 0.98 & 0.98 & 0.99 \\
\hline & $(0.002)$ & $(0.004)$ & $(0.007)$ & $(0.001)$ & $(0.002)$ & $(0.002)$ & $(0.006)$ & $(0.010)$ & $(0.001)$ & $(0.004)$ \\
\hline \multirow[t]{2}{*}{$\gamma$} & -0.11 & 5.23 & -1.6 & 1.43 & 2.65 & 2.05 & 9.43 & 1.43 & -0.005 & 6.45 \\
\hline & $(0.24)$ & $(1.76)$ & $(5.76)$ & $(0.15)$ & $(0.95)$ & $(1.06)$ & $(5.95)$ & $(9.94)$ & $(0.28)$ & $(2.97)$ \\
\hline TJ-test & 8.41 & 8.49 & 7.94 & 8.46 & 8.78 & 7.97 & 8.47 & 8.08 & 9.87 & 9.03 \\
\hline $\mathrm{p}$-value & 0.3 & 0.58 & 0.34 & 0.58 & 0.55 & 0.34 & 0.58 & 0.33 & 0.45 & 0.53 \\
\hline$\delta$ & 1.21 & 1.20 & 1.21 & 1.20 & 1.20 & 1.20 & 1.18 & 1.20 & 1.21 & 1.19 \\
\hline $\operatorname{sigma}(\delta)$ & $(0.29)$ & $(0.29)$ & $(0.29)$ & $(0.29)$ & $(0.29)$ & $(0.29$ & $(0.30)$ & $(0.29)$ & $(0.29)$ & $(0.29)$ \\
\hline$r_{f}$ & 1.42 & -0.04 & 2.17 & 1.19 & 0.64 & 0.68 & -2.58 & 1.11 & 1.83 & -1.23 \\
\hline$r_{m^{-}}-r_{f}$ & -0.01 & 0.25 & -0.08 & 0.07 & 0.13 & 0.1 & 0.45 & 0.07 & 0 & 0.31 \\
\hline \multicolumn{11}{|c|}{ Specification II } \\
\hline \multirow[t]{2}{*}{$\beta$} & 0.98 & 0.98 & 1.00 & 0.98 & 0.98 & 0.98 & 0.99 & 0.99 & 0.98 & 0.98 \\
\hline & $(0.001)$ & $(0.002)$ & $(0.006)$ & $(0.001)$ & $(0.001)$ & $(0.001)$ & $(0.002)$ & $(0.003)$ & $(0.001)$ & $(0.001)$ \\
\hline \multirow[t]{2}{*}{$\gamma$} & 0.66 & 2.75 & -3.26 & 1.51 & 0.48 & -0.43 & 5.98 & -0.7 & 1.43 & 1.69 \\
\hline & $(0.14)$ & $(0.4)$ & (4.09) & $(0.12)$ & $(0.03)$ & $(0.67)$ & 1.85 & (2.7) & $(0.22)$ & $(0.7)$ \\
\hline TJ-test & 9.64 & 9.87 & 8.44 & 9.94 & 9.96 & 9.66 & $(9.91)$ & 9.61 & (10.05) & 9.03 \\
\hline p-value & 0.72 & 0.94 & 0.81 & 0.93 & 0.93 & 0.72 & 0.93 & 0.94 & 0.69 & 0.96 \\
\hline$\delta$ & 1.40 & 1.39 & 1.39 & 1.39 & 1.40 & 1.38 & 1.38 & 1.40 & 1.40 & 1.40 \\
\hline $\operatorname{sigma}(\delta)$ & $(0.29)$ & $(0.29)$ & $(0.29)$ & $(0.29)$ & $(0.29)$ & $(0.30)$ & $(0.30)$ & $(0.29)$ & $(0.29)$ & $(0.29)$ \\
\hline$r_{f}$ & 1.43 & 0.83 & 1.12 & 1.21 & 1.55 & 1.76 & -0.8 & 1.43 & 1.83 & 1.11 \\
\hline$r_{m}-r_{f}$ & 0.03 & 0.13 & -0.15 & 0.07 & 0.02 & -0.02 & 0.28 & -0.03 & 0 & 0.08 \\
\hline
\end{tabular}

Table reports the full sample C-CAPM estimations with iterated GMM. First panel reports the estimation output with aggregate stock index return, returns on risk free bond and long term bond in specification I and specification II adds SMB and HML as test assets to the cross section of returns in specification I. In each panel against the subsequent instrument vector model time and risk preferences are reported in front of row headings $\beta$ and $\gamma$ respectively. The standard errors for the model estimates are given in ().TJ-test is the Hansen's moment identification statistic reported with $\mathrm{p}$-value in []. $\delta$ is the HJ-distance measure computed as in equation (11) section 2.1 and sigma $(\delta)$ reports the asymptotic standard errors for the measure computed in (12) in the same section. The last two rows report the log risk free rate and log equity premia in percentage points estimated from the corresponding setting's time and risk aversion parameters. The coefficients significant at $5 \%$ and below critical values are presented in bold font. The employed instrument vectors are such that

Inst $1=\left(\right.$ Constant $\left., \mathrm{R}_{\mathrm{m}, \mathrm{t}}, \mathrm{R}_{\mathrm{m}, \mathrm{t}-1}\right)$

Inst2 $=\left(\right.$ Constant, $\left.\mathrm{R}_{\mathrm{m}, \mathrm{t}}, \mathrm{R}_{\mathrm{f}, \mathrm{t}} \mathrm{LGB}_{\mathrm{t}}\right)$

Inst3 $=\left(\right.$ Constant, $\left.\mathrm{R}_{\mathrm{m}, \mathrm{t}}, \mathrm{DY}_{\mathrm{t}}\right)$

Inst4 $=\left(\right.$ Constant, $\left.\mathrm{C}_{\mathrm{t}} / \mathrm{C}_{\mathrm{t}-1}, \mathrm{LGB}_{\mathrm{t}}, \mathrm{R}_{\mathrm{f}, \mathrm{t}}\right)$

Inst5 $=\left(\right.$ Constant, $\left.\mathrm{R}_{\mathrm{m}, \mathrm{t}}, \mathrm{DY}_{\mathrm{t},} \mathrm{PER}_{\mathrm{t}}\right)$ 
(a)

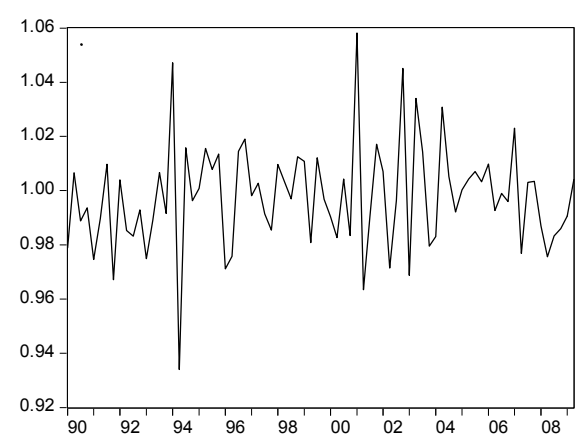

(b)

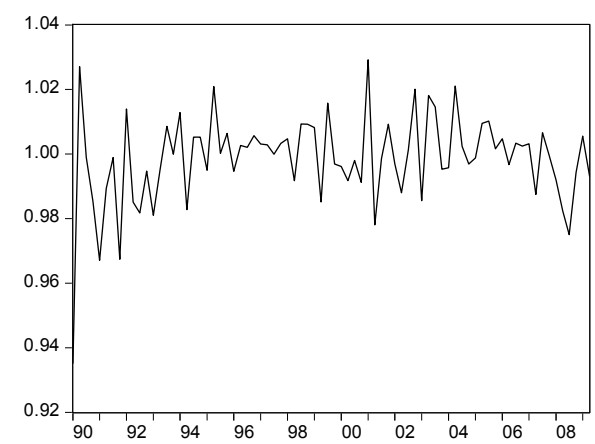

Figure 1. Consumption growth in Finland from 1990Q1:2009:Q2

The growth in figures (a) and (b) shows the changes in Finnish consumption patterns in the Non-Durables and Non-Durables and Services respectively.

(a)

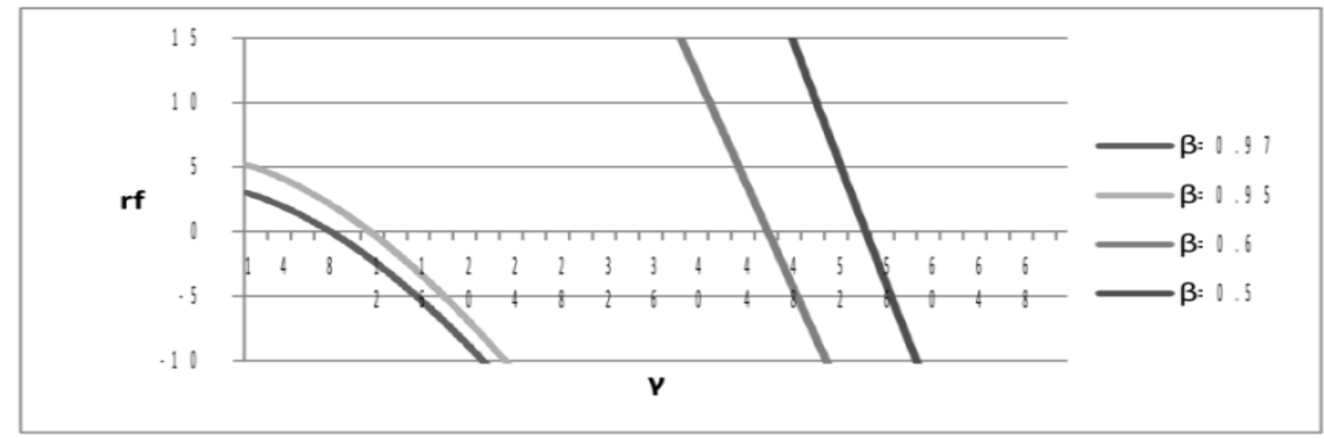

(b)

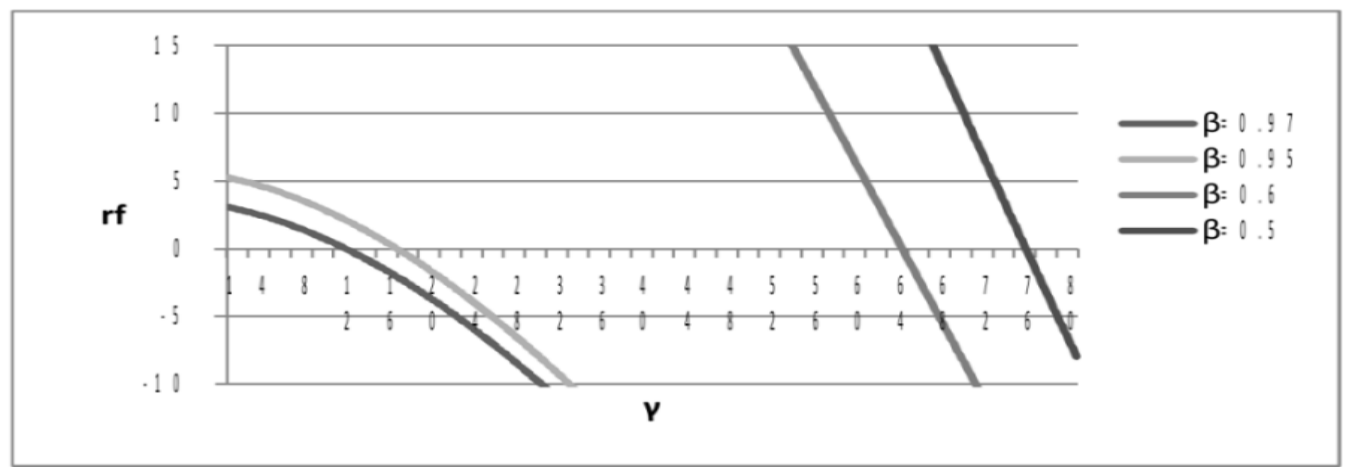

Figure 2. Mean risk free rate vs. RRA estimates

The figures (a) and (b) does the calibrations while using growth in Non-Durables and Non-Durables \& Services as proxy for representative agents' consumption patterns respectively. The figures show simulated risk free rate for different values of RRA coefficient while changing the impatience parameter across the calibrations. 